\title{
Estimasi Parameter Model Poisson Hidden Markov Pada Data Banyaknya Kedatangan Klaim Asuransi Jiwa
}

\author{
Vieri Koerniawan ${ }^{1 *}$, Nurtiti Sunusi ${ }^{2}$, Raupong $^{3}$ \\ 1,2,3 Departemen Statistika, Fakultas MIPA, \\ Universitas Hasanuddin, Makassar, 90245, Indonesia \\ * Corresponding author, email: vieri.koerniawan@gmail.com
}

\begin{abstract}
The Poisson hidden Markov model is a model that consists of two parts. The first part is the cause of events that are hidden or cannot be observed directly and form a Markov chain, while the second part is the process of observation or observable parts that depend on the cause of the event and following the Poisson distribution. The Poisson hidden Markov model parameters are estimated using the Maximum Likelihood Estimator (MLE). But it is difficult to find analytical solutions from the ln-likelihood function. Therefore, the Expectation Maximization (EM) algorithm is used to obtain its numerical solutions which are then applied to life insurance data. The best model is obtained with 2 states or $m=2$ based on the smallest Bayesian Information Criterion (BIC) value of 338,778 and the average predicted number of claims arrivals is 0.385 per day.
\end{abstract}

Keywords: BIC, EM Algorithm, Life Insurance, MLE, Poisson Hidden Markov Model.

\begin{abstract}
Abstrak
Model Poisson hidden Markov merupakan model yang terdiri atas dua bagian. Bagian pertama adalah penyebab peristiwa yang tersembunyi (hidden) atau tidak dapat diamati secara langsung dan membentuk suatu rantai Markov, sedangkan bagian kedua adalah proses observasi atau bagian teramati yang bergantung pada penyebab peristiwa tersebut dan berdistribusi Poisson. Parameter model Poisson hidden Markov diestimasi menggunakan Maximum Likelihood Estimator (MLE). Namun sulit untuk menemukan solusi analitik dari fungsi In-likelihood-nya. Oleh karena itu, digunakan algoritma Expectation Maximization (EM) untuk memperoleh solusi numeriknya kemudian diaplikasikan pada data asuransi jiwa. Model terbaik diperoleh dengan 2 state atau $m=2$ berdasarkan nilai Bayesian Information Criterion (BIC) terkecil yaitu 338.778 dan prediksi rata-rata banyaknya kedatangan klaim adalah sebesar 0.385 perhari.
\end{abstract}

Kata Kunci: Algoritma EM, Asuransi Jiwa, BIC, MLE, Model Poisson Hidden Markov.

\section{Pendahuluan}

Hampir semua fenomena atau peristiwa yang terjadi di alam ini bersifat acak atau probabilistik. Suatu proses yang dapat memprediksi ataupun menjelaskan fenomenafenomena tersebut dinamakan proses stokastik. Proses Poisson merupakan salah satu proses stokastik yang pembentukannya didasarkan pada distribusi Poisson dan sifat-sifat keindependenannya. Jika suatu variabel acak berdistribusi Poisson maka mean dan variansinya diasumsikan bernilai sama [1]. Namun, pada penerapannya dalam kehidupan sehari-hari, seringkali terjadi pelanggaran asumsi berupa overdispersi.

Estimasi: Journal of Statistics and Its Application

e-ISSN: 2721-3803, p-ISSN: 2721-379X

http://journal.unhas.ac.id/index.php/ESTIMASI 
Overdispersi adalah suatu kondisi dengan variabel acak memiliki nilai variansi yang lebih besar daripada nilai meannya. Penyebab terjadinya overdispersi adalah terdapat pengaruh variabel lain atau sumber keragaman lain dari suatu peristiwa yang tidak dapat diamati secara langsung yang mengakibatkan probabilitas terjadinya suatu peristiwa bergantung pada peristiwa sebelumnya [2]. Penyebab dari peristiwa tersebut terkadang membentuk suatu rantai Markov.

Rantai Markov (Markov chain) merupakan suatu proses stokastik yang menyatakan bahwa probabilitas bersyarat dari suatu peristiwa masa depan dengan diketahui peristiwa masa lalu dan masa kini adalah tidak bergantung pada peristiwa masa lalu tetapi hanya bergantung pada peristiwa masa kini. Salah satu bentuk khusus dari rantai Markov adalah model hidden Markov. Model hidden Markov adalah model dengan waktu diskrit yang terdiri atas dua bagian. Bagian pertama adalah penyebab peristiwa yang tersembunyi (hidden) atau tidak dapat diamati secara langsung dan membentuk suatu rantai Markov, sedangkan bagian kedua adalah proses observasi atau bagian teramati yang bergantung pada penyebab peristiwa tersebut. Model hidden Markov pertama kali dikembangkan oleh Paroli dan Spezia (1999) dengan mengasumsikan proses dari bagian yang teramati merupakan variabel acak berdistribusi Gaussian sehingga dinamakan dengan model Gaussian hidden Markov [3]. Selanjutnya, Paroli et al. (2000) kembali mengembangkan model hidden Markov dengan mengasumsikan proses dari bagian yang teramati merupakan variabel acak berdistribusi Poisson sehingga dinamakan dengan model Poisson hidden Markov [4].

Parameter model Poisson hidden Markov dapat diestimasi menggunakan maximum likelihood estimator (MLE). Tetapi, pada umumnya sulit untuk mendapatkan solusi analitik dari persamaan likelihood-nya. Oleh karena itu, digunakanlah algoritma expectation maximization (EM) agar diperoleh solusi numeriknya [5]. Salah satu aplikasi dari model Poisson hidden Markov adalah prediksi kedatangan klaim asuransi jiwa.

Asuransi jiwa adalah suatu program perlindungan yang bertujuan untuk menanggung seseorang terhadap kerugian finansial tak terduga. Klaim asuransi jiwa dapat dilakukan apabila tertanggung mengalami risiko kehilangan jiwa. Estimasi banyaknya kedatangan klaim dapat membantu pihak asuransi untuk mempersiapkan cadangan klaim untuk dibayarkan kepada pihak tertanggung apabila mengalami risiko yang tidak dapat diketahui secara pasti waktu terjadinya. Proses kedatangan klaim asuransi jiwa dapat diasumsikan mengikuti distribusi Poisson karena probabilitas tertanggung mengalami risiko kehilangan jiwa sangat kecil. Proses kedatangan klaim asuransi jiwa juga sangat erat kaitannya dengan penyebab terjadinya, namun penyebab dari peristiwa tersebut tidak dapat diamati secara langsung. Jika penyebab dari peristiwa tersebut diasumsikan membentuk rantai Markov dan proses kedatangan klaim diasumsikan mengikuti berdistribusi Poisson maka pasangan proses kedatangan klaim dan penyebabnya dapat dimodelkan dengan model Poisson hidden Markov. 


\section{Material dan Metode}

\subsection{Model Poisson Hidden Markov}

Model Hidden Markov adalah proses stokastik dengan waktu diskrit, terdiri atas pasangan $\left\{X_{t}, Y_{t} ; t \in \mathbb{N}\right\} .\left\{X_{t}, t \in \mathbb{N}\right\}$ merupakan penyebab peristiwa yang tidak diamati secara langsung dan membentuk suatu rantai Markov. Sedangkan $\left\{Y_{t}, t \in \mathbb{N}\right\}$ adalah proses observasi yang bergantung pada $\left\{\mathrm{X}_{\mathrm{t}}, t \in \mathbb{N}\right\}$. Model Poisson hidden Markov dapat digunakan untuk mengatasi gejala overdispersi, yaitu nilai variansinya lebih besar dari nilai ekspektasinya.

Adapun karakteristik dari model Poisson hidden Markov dapat dituliskan seperti berikut ini

1. $\left\{X_{t}, t \in \mathbb{N}\right\}$ diasumsikan membentuk rantai Markov diskrit, homogen, aperiodik dan tak tereduksi dengan ruang state $S_{x}=\{1,2, \ldots, m\}$

2. Matriks probabilitas state transisi $\Gamma=\left[\gamma_{i j}\right]$, dimana $\Gamma$ matriks berukuran $m \times m$ dengan $i, j \in S_{x}$ memenuhi

$$
\gamma_{i j}=P\left(\mathrm{X}_{t+1}=j \mid \mathrm{X}_{t}=i\right)=P\left(\mathrm{X}_{2}=j \mid \mathrm{X}_{1}=i\right), \quad \gamma_{i j} \geq 0
$$

dan $\sum_{j=1}^{m} \gamma_{i j}=1, i=1,2, \ldots, m$

3. Dalam model Poisson hidden Markov, saat $X_{t}$ berada pada state $i$ untuk setiap $i \in$ $S_{x}$ maka distribusi bersyarat dari variabel $Y_{t}$ jika diketahui $X_{t}=i$ untuk setiap $t \in \mathbb{N}$ adalah fungsi densitas probabilitas variabel acak Poisson dengan parameter $\lambda_{i}$, yaitu

$$
\pi_{y i}=P\left(Y_{t}=y \mid X_{t}=i\right)=e^{-\lambda_{i}} \frac{\lambda_{i}^{y}}{y !},
$$

untuk setiap $y \in \mathbb{N}$ dan $\sum_{y \in \mathbb{N}} \pi_{y i}=1$

4. Untuk setiap $t \in \mathbb{N}$, vektor probabilitas state awal (initial) dilambangkan $\boldsymbol{\delta}=\left[\delta_{i}\right]$, dimana $\boldsymbol{\delta}$ berukuran $m \times 1$ dan $i \in S_{x}$ dengan

$$
\delta_{i}=P\left(\mathrm{X}_{t}=i\right)
$$

dan $\sum_{i=1}^{m} \delta_{i}=1$ serta $\boldsymbol{\delta}$ memenuhi persamaan

$$
\boldsymbol{\delta}=\left(\mathrm{I}_{m \times m}-\Gamma+1_{m \times m}\right)^{-1} \mathbf{1}_{\boldsymbol{m}}
$$

5. Untuk setiap $t \in \mathbb{N}$, fungsi distribusi marginal dari $Y_{t}$ adalah

$$
P\left(Y_{t}=y\right)=\sum_{i=1}^{m} P\left(Y_{t}=y, X_{t}=i\right)=\sum_{i=1}^{m} \delta_{i} \pi_{y i}
$$

Berdasarkan karakteristik di atas, model Poisson hidden Markov $\left\{\mathrm{X}_{t}, \mathrm{Y}_{t} ; t \in \mathbb{N}\right\}$ oleh parameter $\boldsymbol{\delta}$ dan $\boldsymbol{\theta}=(\Gamma, \lambda)^{\prime}$ dengan $\boldsymbol{\delta}=\left[\delta_{i}\right], \quad i \in S_{x}, \Gamma=\left[\gamma_{i j}\right], i, j \in S_{x}, \boldsymbol{\lambda}=$ $\left[\lambda_{i}\right], \quad i \in S_{x}$ dan ukuran parameter yang akan diestimasi adalah sebanyak $m^{2}-m$ elemen dari matriks probabilitas transisi $\Gamma=\left[\gamma_{i j}\right]$ karena untuk setiap diagonalnya berlaku $\gamma_{i i}=1-\sum_{j=1}^{m} \gamma_{i j}, j \neq i, i \in S_{x}$, serta sebanyak $m$ elemen dari vekor $\lambda$ 
sehingga diperoleh ukuran parameter model Poisson hidden Markov $\boldsymbol{\theta}=(\Gamma, \lambda)^{\prime}$ yang akan diestimasi adalah $\left(m^{2}-m\right)+m=m^{2}[4]$.

\subsection{Maximum Likelihood Estimation}

Misalkan $\boldsymbol{y}=\left(y_{1}, y_{2}, \ldots, y_{T}\right)^{\prime}$ adalah vektor dari data observasi. Vektor $\boldsymbol{y}$ adalah vektor yang tak lengkap karena vektor dari data yang tidak diamati, yaitu $\left\{\mathrm{X}_{t}, t \in \mathbb{N}\right\}$ tidak ada. Misalkan $\boldsymbol{x}=\left(i_{1}, i_{2}, \ldots, i_{T}\right)^{\prime}$ adalah vektor dari data yang tidak diamati (hidden). Fungsi likelihood dari $\boldsymbol{y}$ dapat dituliskan sebagai berikut

$$
L_{T}\left(\boldsymbol{\theta} ; Y_{t}=y\right)=P\left(Y_{1}=y_{1}, \ldots, Y_{T}=y_{T} ; \boldsymbol{\theta}\right),
$$

dengan $\boldsymbol{\theta}=(\Gamma, \lambda)^{\prime}$ adalah vektor parameter untuk setiap $\boldsymbol{\theta} \in \Omega$ dan $t \in\{1,2, \ldots, T\}$ dan fungsi likelihood dari $(\boldsymbol{x}, \boldsymbol{y})$ yaitu untuk data lengkap adalah [4]

$$
L_{T}^{c}\left(\boldsymbol{\theta} ; X_{t}=i, Y_{t}=y\right)=P\left(X_{1}=i_{1}, \ldots, X_{T}=i_{T}, Y_{1}=y_{1}, \ldots, Y_{T}=y_{T} ; \boldsymbol{\theta}\right) .
$$

Untuk menentukan mle, biasanya diambil nilai logaritma natural $(\ln )$ dari fungsi likelihood agar diperoleh nilai ekstrim yang memaksimumkan fungsi sehingga solusi dari MLE diberikan oleh [6]

$$
\left.\frac{\partial L_{T}\left(\boldsymbol{\theta} ; Y_{t}=y\right)}{\partial \boldsymbol{\theta}}\right|_{\boldsymbol{\theta}=\widehat{\boldsymbol{\theta}}}=0
$$

\subsection{Algoritma Expectation Maximization}

Algoritma Expectation Maximization (EM) merupakan salah satu algoritma numerik yang digunakan untuk mencari solusi dari suatu persamaan. Algoritma EM dapat digunakan untuk mendapatkan nilai MLE yang sangat sulit diperoleh solusi analitiknya. Algoritma EM dapat menemukan estimator parameter $\boldsymbol{\theta}$ pada persamaan dari data yang tidak lengkap. Algoritma merupakan algoritma iteratif yang terdiri dari dua langkah pada setiap iterasinya. Langkah pertama adalah langkah E (E-step) untuk menghitung ekspektasi dari data tidak lengkap dan langkah kedua adalah M (M-step) untuk memaksimumkan nilai ekspektasi yang telah diperoleh sebelumnya.

Misalkan diambil $\boldsymbol{\theta}^{(k)}$ sebagai estimator parameter model Poisson hidden Markov yang diperoleh pada iterasi ke- $(k)$, dengan $\boldsymbol{\theta}^{(k)}=\left(\Gamma^{(k)}, \lambda^{(k)}\right)^{\prime}$. Langkah E dan langkah $M$ didefinisikan sebagai berikut

1. E-step, diberikan $\boldsymbol{\theta}^{(k)}$ hitung

$$
\begin{aligned}
Q\left(\boldsymbol{\theta} ; \boldsymbol{\theta}^{(k)}\right) & =E\left(\ln L_{T}^{c}(\boldsymbol{\theta}) \mid y\right) \\
& =\sum_{i_{1}=1}^{m} \ldots \sum_{i_{T}=1}^{m}\left[\ln L_{T}^{c}(\boldsymbol{\theta} ; x, y) p(x \mid y ; \boldsymbol{\theta})\right],
\end{aligned}
$$

2. M-step, cari $\boldsymbol{\theta}^{(k)}$ yang memaksimumkan $Q\left(\boldsymbol{\theta} ; \boldsymbol{\theta}^{(k)}\right)$ dinotasikan

$$
\boldsymbol{\theta}^{(k)} \in \operatorname{argmax} Q\left(\boldsymbol{\theta} ; \boldsymbol{\theta}^{(k)}\right),
$$

sehingga 


$$
Q\left(\boldsymbol{\theta}^{(k+1)} ; \boldsymbol{\theta}^{(k)}\right) \geq Q\left(\boldsymbol{\theta} ; \boldsymbol{\theta}^{(k)}\right)
$$

Langkah E dan M diulang hingga $\left\{\ln L_{T}\left(\boldsymbol{\theta}^{(k+1)}\right)\right\}_{k=1}^{\infty}$ konvergen atau selisih

$$
\left|\ln L_{T}\left(\boldsymbol{\theta}^{(k+1)}\right)-\ln L_{T}\left(\boldsymbol{\theta}^{(k)}\right)\right|
$$

kurang dari kesalahan (error) yang diinginkan.

Jika algoritma konvergen pada iterasi ke- $(k+1)$ maka dapat dikatakan $\boldsymbol{\theta}^{(k+1)}$ dan $\ln L_{T}\left(\boldsymbol{\theta}^{(k+1)}\right)$ adalah titik stasioner dan $\boldsymbol{\theta}^{(k+1)}=\left(\Gamma^{(k+1)}, \boldsymbol{\lambda}^{(k+1)}\right)^{\prime}$ adalah estimator maksimum dari fungsi likelihood [4].

\subsection{Bayesian Information Criterion}

Bayesian Information Criterion (BIC) digunakan untuk mengestimasi dimensi dari model. Nilai BIC yang lebih kecil merepresentasikan keseimbangan optimum antara kecocokan model dengan banyaknya parameter, sehingga model yang lebih baik adalah model dengan nilai BIC minimum. Nilai BIC dirumuskan sebagai berikut

$$
B I C=-2 \ln L_{T}^{m}(\boldsymbol{\theta})+m^{2}(\ln T),
$$

dengan $L_{T}^{m}(\boldsymbol{\theta})$ adalah fungsi In-likelihood yang dimaksimumkan terhadap model Poisson hidden Markov dan $m$ adalah banyak state.

\subsection{Metode Penelitian}

Data yang digunakan adalah data sekunder yang bersumber dari perusahaan asuransi PT. Avrist Assurance Indonesia. Data merupakan banyaknya kedatangan klaim untuk asuransi jiwa seumur hidup yang terjadi dalam jangka waktu mulai tanggal 14 Februari 2019 sampai dengan 29 Agustus 2019. Periode observasi yang digunakan adalah data harian sehingga terdapat 197 barisan data observasi Selama periode waktu tersebut, terdapat 78 tertanggung yang mengajukan klaim.

Proses observasi, dalam hal ini adalah data banyaknya kedatangan klaim yang dapat diamati secara langsung, bergantung pada penyebab terjadinya pada waktu $t$ dinyatakan dalam variabel acak $Y_{t}$ dan penyebab dari terjadinya proses observasi (pengajuan klaim) yang tidak dapat diamati secara langsung (proses tersembunyi) pada waktu $t$ dinyatakan dalam variabel acak $X_{t}$.

Langkah-langkah yang dilakukan untuk menganalisis data dalam penelitian ini adalah sebagai berikut:

1. Melakukan langkah E dengan menghitung $Q\left(\boldsymbol{\theta} ; \boldsymbol{\theta}^{(\boldsymbol{k})}\right)$

2. Melakukan langkah $M$ dengan mencari $\boldsymbol{\theta}^{(\boldsymbol{k})}$ yang memaksimumkan $Q\left(\boldsymbol{\theta} ; \boldsymbol{\theta}^{(\boldsymbol{k})}\right)$

3. Menghitung nilai estimator parameter $\boldsymbol{\theta}^{(\boldsymbol{k})}=\left(\Gamma^{(k)}, \boldsymbol{\lambda}^{(k)}\right)^{\prime}$

4. Menghitung nilai estimator parameter $\boldsymbol{\delta}^{(k)}$

5. Mengganti $k$ dengan $k+1$ hingga $\left\{\ln L_{T}\left(\boldsymbol{\theta}^{(\boldsymbol{k})}\right)\right\}$ konvergen $\mid \ln L_{T}\left(\boldsymbol{\theta}^{(\boldsymbol{k}+\mathbf{1})}\right)-$ $\ln L_{T}\left(\boldsymbol{\theta}^{(k)}\right) \mid$ kurang dari kesalahan (error) yang diinginkan, yaitu $\varepsilon=10^{-6}$

6. Menghitung nilai BIC untuk $m=2,3,4,5$. 
7. Memilih nilai BIC paling minimum agar diperoleh $m$ yang terbaik.

\section{Hasil dan Diskusi}

\subsection{Estimasi Parameter Model Poisson Hidden Markov}

Misalkan bahwa $P\left(X_{1}=i_{1}, \ldots, X_{T}=i_{T}, Y_{1}=y_{1}, \ldots, Y_{t}=Y_{T} ; \boldsymbol{\theta}\right)=p(x, y ; \boldsymbol{\theta})$ adalah fungsi densitas probabilitas bersama dari pasangan variabel acak $\left\{X_{t}, Y_{t} ; t \in \mathbb{N}\right\}$ maka fungsi likelihood-nya adalah

$L_{T}^{c}\left(\boldsymbol{\theta} ; X_{t}=i, Y_{t}=y\right)=P\left(X_{1}=i_{1}, \ldots, X_{T}=i_{T}, Y_{1}=y_{1}, \ldots, Y_{T}=y_{T} ; \boldsymbol{\theta}\right)=p(x, y ; \boldsymbol{\theta})$, dan misalkan bahwa $P\left(Y_{1}=y_{1}, \ldots, Y_{T}=y_{T} ; \boldsymbol{\theta}\right)=p(y ; \boldsymbol{\theta})$ adalah fungsi densitas probabilitas dari variabel acak $\left\{Y_{t} ; t \in \mathbb{N}\right\}$ maka fungsi likelihood-nya adalah

$$
L_{T}\left(\boldsymbol{\theta} ; Y_{t}=y\right)=P\left(Y_{1}=y_{1}, \ldots, Y_{T}=y_{T} ; \boldsymbol{\theta}\right)=p(y ; \boldsymbol{\theta}) .
$$

Selanjutnya, misalkan bahwa $P\left(X_{1}=i_{1}, \ldots, X_{T}=i_{T} \mid Y_{1}=y_{1}, \ldots, Y_{t}=Y_{T} ; \boldsymbol{\theta}\right)=$ $p(x \mid y ; \boldsymbol{\theta})$ adalah fungsi densitas probabilitas dari $\left\{X_{t}, t \in \mathbb{N}\right\}$ diberikan $\left\{Y_{t}, t \in \mathbb{N}\right\}$, sehingga

$$
p(x \mid y ; \boldsymbol{\theta})=\frac{p(x, y ; \boldsymbol{\theta})}{p(y ; \boldsymbol{\theta})}=\frac{L_{T}^{c}(\boldsymbol{\theta} ; x, y)}{L_{T}(\boldsymbol{\theta} ; y)}
$$

atau dapat dituliskan

$$
\ln L_{T}(\boldsymbol{\theta} ; y)=\ln L_{T}^{c}(\boldsymbol{\theta} ; x, y)-\ln p(x \mid y ; \boldsymbol{\theta}) .
$$

Estimator parameter $\widehat{\boldsymbol{\theta}}=(\hat{\Gamma}, \hat{\boldsymbol{\lambda}})^{\prime}$ dapat diperoleh dengan memaksimumkan nilai $\ln L_{T}(\boldsymbol{\theta} ; y)$ sedemikian sehingga $\frac{\partial L_{T}(\boldsymbol{\theta} ; y)}{\partial \boldsymbol{\theta}}=0$. Namun nilai $\ln L_{T}(\boldsymbol{\theta} ; y)$ yang maksimum tidak dapat diperoleh secara analitik, karena $L_{T}(\boldsymbol{\theta} ; y)$ merupakan fungsi likelihood dari data yang tidak lengkap. Oleh karena itu, digunakan algoritma EM.

\subsection{Algoritma Expectation Maximization}

Algoritma EM merupakan algoritma numerik yang secara umum digunakan untuk mendapatkan MLE secara tidak langsung dalam keadaan dengan data tidak lengkap.

1. Langkah Ekspektasi (E-step)

E-step dilakukan dengan menghitung nilai ekspektasi dari fungsi ln-likelihood $\ln L_{T}(\boldsymbol{\theta} ; y)$ sehingga

$$
\begin{aligned}
\ln L_{T}(\boldsymbol{\theta} ; y) & =E\left[\ln L_{T}^{c}(\boldsymbol{\theta} ; x, y) \mid y\right]-E[\ln p(x \mid y ; \boldsymbol{\theta}) \mid y] \\
& =Q\left(\boldsymbol{\theta} ; \boldsymbol{\theta}^{(k)}\right)-H\left(\boldsymbol{\theta} ; \boldsymbol{\theta}^{(k)}\right),
\end{aligned}
$$

dengan $Q\left(\boldsymbol{\theta} ; \boldsymbol{\theta}^{(k)}\right)=E\left[\ln L_{T}^{c}(\boldsymbol{\theta} ; x, y) \mid y\right] \operatorname{dan} H\left(\boldsymbol{\theta} ; \boldsymbol{\theta}^{(k)}\right)=E[\ln p(x \mid y ; \boldsymbol{\theta}) \mid y]$.

2. Langkah Maksimisasi (M-step)

Pada M-step dari algoritma EM akan dimaksimumkan fungsi ln-likelihood dari $\ln L_{T}(\boldsymbol{\theta} ; y)$. Persamaan (4.6) akan dimaksimumkan dengan mencari turunan pertama dari bentuk $Q\left(\boldsymbol{\theta} ; \boldsymbol{\theta}^{(k)}\right)-H\left(\boldsymbol{\theta} ; \boldsymbol{\theta}^{(k)}\right)$, yaitu 


$$
\frac{\partial \ln L_{T}(\boldsymbol{\theta} ; y)}{\partial \boldsymbol{\theta}}=\frac{\partial Q\left(\boldsymbol{\theta} ; \boldsymbol{\theta}^{(k)}\right)}{\partial \boldsymbol{\theta}}-\frac{\partial H\left(\boldsymbol{\theta} ; \boldsymbol{\theta}^{(k)}\right)}{\partial \boldsymbol{\theta}} .
$$

Menurut Dempster et al. (1977) dalam Paroli et al. (1999) hasil turunan dari $H\left(\boldsymbol{\theta} ; \boldsymbol{\theta}^{(k)}\right)$ adalah sama dengan nol [7].

Oleh karena itu, fungsi yang akan dimaksimumkan untuk mengestimasi parameter $\boldsymbol{\theta}$ hanya $Q\left(\boldsymbol{\theta} ; \boldsymbol{\theta}^{(k)}\right)$ sehingga $\ln L_{T}(\boldsymbol{\theta} ; y)$ akan maksimum, dengan $k$ adalah banyak iterasi. Jadi terlebih dahulu dicari fungsi $Q\left(\boldsymbol{\theta} ; \boldsymbol{\theta}^{(k)}\right)$ dengan

$$
\begin{aligned}
Q\left(\boldsymbol{\theta} ; \boldsymbol{\theta}^{(k)}\right) & =E\left[\ln L_{T}^{c}(\boldsymbol{\theta} ; x, y) \mid y\right] \\
& =\sum_{i_{1}=1}^{m} \ldots \sum_{i_{T}=1}^{m}\left[\ln L_{T}^{c}\left(\boldsymbol{\theta}^{(\boldsymbol{k})} ; x, y\right) p\left(x \mid y ; \boldsymbol{\theta}^{(\boldsymbol{k})}\right)\right]
\end{aligned}
$$

Sehingga diperoleh

$$
\begin{aligned}
Q\left(\boldsymbol{\theta} ; \boldsymbol{\theta}^{(\boldsymbol{k})}\right)= & \sum_{i=1}^{m} \sum_{j=1}^{m} \frac{\sum_{t=1}^{T-1} a_{t}{ }^{(k)}(i) \pi_{y_{t+1} i_{t}{ }^{(k)} b_{t+1}{ }^{(k)}(j) \gamma_{i j}{ }^{(k)}}}{\sum_{l=1}^{m} a_{t}{ }^{(k)}(l) b_{t}{ }^{(k)}(l)} \ln \gamma_{i j} \\
& +\sum_{i=1}^{m} \frac{\sum_{t=1}^{T} a_{t}{ }^{(k)}(i) b_{t}{ }^{(k)}(i)}{\sum_{l=1}^{m} a_{t}{ }^{(k)}(l) b_{t}{ }^{(k)}(l)} \ln \pi_{y_{t} i} .
\end{aligned}
$$

Selanjutnya, fungsi $Q\left(\boldsymbol{\theta} ; \boldsymbol{\theta}^{(\boldsymbol{k})}\right)$ dimaksimumkan agar diperoleh estimator parameter $\gamma_{i j}$ dan $\lambda_{i}$, yaitu

$$
\hat{\gamma}_{i j}=\frac{\sum_{t=1}^{T-1} a_{t}{ }^{(k)}(i) \pi_{y_{t+1}{ }^{(k)} b_{t+1}{ }^{(k)}(j) \gamma_{i j}{ }^{(k)}}}{\sum_{t=1}^{T-1} a_{t}{ }^{(k)}(i) \pi_{y_{t+1} j^{(k)} b_{t}{ }^{(k)}(j)}}
$$

dan

$$
\widehat{\lambda}_{\imath}=\frac{\sum_{t=1}^{T} a_{t}^{(k)}(i) b_{t}^{(k)}(i) y_{t}}{\sum_{t=1}^{T} a_{t}^{(k)}(i) b_{t}^{(k)}(i)},
$$

dengan

$$
a_{t}(i)=\left(\sum_{j=1}^{m} a_{t-1}(j) \gamma_{i j}\right) \pi_{y_{t} i}
$$

dan

$$
b_{t}(j)=\sum_{i=1}^{m} \pi_{y_{t+1} i} b_{t+1}(i) \gamma_{i j} \text { adalah probabilitas forward-backward. }
$$

\subsection{Penentuan Nilai Parameter Model Poisson Hidden Markov pada Data Banyaknya Kedatangan Klaim Asuransi Jiwa}

Nilai estimator parameter model Poisson hidden Markov untuk $m=2,3,4,5$ dihitung menggunakan estimator parameter pada persamaan (12), (13) dan (3), nilai lnlikelihood untuk masing-masing $m$ dihitung menggunakan persamaan (11) serta nilai 
BIC menggunakan persamaan (10) dengan bantuan software Mathematica 11.3.0. Sehingga diperoleh Tabel 1 berikut ini.

Tabel 1. Nilai Loglikelihood dan AIC

\begin{tabular}{ccc}
\hline$m$ & ln-likelihood & BIC \\
\hline 2 & -158.834 & 338.778 \\
3 & -156.741 & 361.029 \\
4 & -153.328 & 391.184 \\
5 & -152.109 & 436.294 \\
\hline
\end{tabular}

Sumber: Data diolah 2020

Dari hasil yang diperoleh dapat dilihat bahwa nilai BIC terkecil adalah sebesar 338.778 yaitu untuk banyak state adalah 2 sehingga dapat dikatakan bahwa nilai $m=2$ merupakan nilai yang terbaik untuk estimasi parameter model. Sehingga diperoleh matriks probabilitas transisi penyebab terjadinya proses kedatangan klaim asuransi jiwa yang memaksimumkan fungsi ln-likelihood, yaitu

$$
\widehat{\Gamma}=\left(\begin{array}{ll}
0.964 & 0.036 \\
0.953 & 0.047
\end{array}\right) \text {. }
$$

Nilai tersebut menyatakan bahwa setelah terjadinya kedatangan klaim oleh penyebab keadaan pertama akan terjadi lagi oleh penyebab dari keadaan pertama dengan probabilitas sebesar 0.964 serta terjadi lagi oleh penyebab keadaan kedua dengan probabilitas sebesar 0.036. Selanjutnya, setelah terjadinya kedatangan klaim oleh penyebab keadaan kedua akan terjadi lagi oleh penyebab keadaan pertama dengan probabilitas sebesar 0.953 serta terjadi lagi oleh penyebab keadaan kedua dengan probabilitas sebesar 0.047 .

Selanjutnya, diperoleh nilai vektor estimator parameter dari distribusi Poisson, yaitu

$$
\hat{\lambda}=\left(\begin{array}{l}
0.259 \\
3.672
\end{array}\right) \text {. }
$$

Nilai tersebut menyatakan bahwa laju kedatangan klaim oleh penyebab keadaan pertama adalah sebesar 0.259 per hari, sedangkan laju kedatangan klaim oleh penyebab keadaan kedua adalah sebesar 3.672 per hari. Kemudian, diperoleh vektor probabilitas state awal berdasarkan persamaan (3), yaitu

$$
\widehat{\boldsymbol{\delta}}=\left(\begin{array}{l}
0.963 \\
0.037
\end{array}\right) \text {. }
$$

Nilai tersebut menyatakan bahwa probabilitas terjadinya kedatangan klaim karena penyebab keadaan pertama adalah sebesar 0.963 dan probabilitas terjadinya kedatangan klaim karena penyebab keadaan kedua adalah sebesar 0.037 . 


\section{Kesimpulan}

Model Poisson hidden Markov terbaik pada data banyaknya kedatangan klaim asuransi jiwa berdasarkan kriteria BIC, yaitu nilai BIC yang paling minimum adalah dengan $m=2$ atau dua penyebab (2 state) sehingga diperoleh nilai estimator parameter sebagai berikut

$$
\begin{gathered}
\hat{\Gamma}=\left(\begin{array}{ll}
0.964 & 0.036 \\
0.953 & 0.047
\end{array}\right) \\
\hat{\boldsymbol{\lambda}}=\left(\begin{array}{l}
0.259 \\
3.672
\end{array}\right) \\
\widehat{\boldsymbol{\delta}}=\left(\begin{array}{l}
0.963 \\
0.037
\end{array}\right)
\end{gathered}
$$

Penelitian dapat dilanjutkan untuk mencari apa faktor penyebab proses yang sesuai dengan banyak penyebab yang telah diperoleh.

\section{Daftar Pustaka}

[1] Taylor, H. M., dan Karlin, S. An Introduction to Stochastic Modeling, Third Edition. San Diego: Academic Press. 1998.

[2] Long, J. S. Regression Models for Categorical and Limited Dependent Variables. California: Sage. 1997.

[3] Paroli, R., dan Spezia, L. Gaussian Hidden Markov Models: Parameters Estimation and Applications to Air Pollution Data. Milano: Universita Cattolica Del Sacro Coure. 1999.

[4] Paroli, R., Redaelli, G., dan Spezia, L. Poisson Hidden Markov Models for Time Series of Overdispersed Insurance Count. Astin Colloquium, 461-474, 2000.

[5] Gustra, H. Pemodelan Klaim Asuransi Kerugian Menggunakan Poisson Hidden Markov untuk Data Overdispersi. Bogor: Institut Pertanian Bogor. 2014.

[6] Hogg, R. V., Craig, A. T., dan McKean, J. W. Introduction to Mathematical Statistics, Sixth Edition. New Jersey: Prentice Hall. 2005.

[7] Dempster, A. P., Laird, N., dan Rubin, D. B. Maximum Likelihood from Incomplete Data via the EM Algorithm. Journal of the Royal Statistical Society, 39 (1) : 1-38, 1977. 